\title{
Acceptance and Commitment Therapy for Patients with a First Psychotic Episode
}

\author{
Применение психотерапевтического подхода «Терапия принятия \\ и ответственности" у пациентов с первым психотическим эпизодом \\ doi: $10.17816 /$ CP97
}

Review

\author{
Nikita V. Chernov, Tatiana V. Moiseeva, \\ Maria A. Belyakova, Maria D. Polyakova, \\ Marta V. Sozinova \\ Mental Health Clinic No. 1 named after N.A. Alexeev, \\ Moscow, Russia \\ The article can be used under the CC BY-NC-ND 4.0 license \\ (c) Authors, 2021
}

\author{
Никита В. Чернов, Татьяна В. Моисеева, \\ Мария А. Белякова, Мария Д. Полякова, \\ Марта В. Созинова \\ ГБУЗ «ПКБ № 1 им. Н.А. Алексеева ДЗМ», Москва, Россия
}

\author{
Лицензия CC BY-NC-ND 4.0
}

(c) Коллектив авторов, 2021

\begin{abstract}
The search for the most effective methods of therapy for mental disorders is a priority for modern psychiatry. An approach to the early diagnostics and rehabilitation of patients experiencing psychotic episodes for the first time is proposed in the present article. The proposed approach is based on the combination of drug therapy and acceptance and commitment therapy (ACT) characterized by the development of the patient's psychological flexibility, rather than controlling the disease symptoms. The article describes the main processes of the ACT model: acceptance, cognitive defusion, contact with the present moment, understanding of the inner world, awareness of significant values, and the regulation of purposeful behaviour for the implementation of these values. Recommendations for different stages of treatment were also developed by specialists of the First Psychotic Episode Clinic at the Mental Health Clinic No.1 named after N.A. Alexeev. The psychological rehabilitation of patients with the use of ACT in the case of psychotic disorders with both negative and positive symptoms was elaborated. The application of acceptance and commitment therapy in the early diagnostics and treatment of patients experiencing a first psychotic episode results in fewer readmissions and improved psychosocial functioning in both inpatient and outpatient care.
\end{abstract}

\section{АНнОТАЦИЯ}

Поиск наиболее эффективных методов лечения больных с психическими расстройствами имеет приоритетное значение для современной психиатрии. В статье рассматривается подход к ранней диагностике и реабилитации пациентов, впервые переживающих психотический эпизод. В основе него лежит сочетание медикаментозной терапии и психотерапевтического подхода «Терапия принятия и ответственности» (ТПО), отличительной особенностью которого является не борьба с симптомами заболевания, а развитие психологической гибкости пациента. В статье описаны основные мишени психотерапевтической работы в рамках модели ТПО: принятие, когнитивное распутывание, связь с настоящим моментом, понимание внутреннего мира, осознание значимых ценностей и регуляция целенаправленного поведения по реализации этих ценностей. Разработаны также рекомендации для разных этапов лечения в Клинике первого психотического эпизода на базе ГБУЗ «ПКБ № 1 
им. Н.А. Алексеева ДЗМ». Конкретизирована психологическая реабилитация пациентов с применением ТПО при психотических расстройствах как с негативной, так и с продуктивной симптоматикой. Результатом применения ТПО в ранней диагностике и лечении пациентов с первым психотическим эпизодом является снижение количества повторных госпитализаций и улучшение психосоциального функционирования как при стационарном, так и при амбулаторном лечении.

Keywords: acceptance and commitment therapy; schizophrenia; distress; first psychotic episode

Ключевые слова: терапия принятия и ответственности; шизофрения; дистресс; первый психотический эпизод

\section{INTRODUCTION}

The first psychotic episode is considered the period with the greatest therapeutic opportunities for various primary psychotic disorders. ${ }^{1,2}$ On the one hand, this group of patients has a higher rehabilitation potential, whilst on the other, they are the most sensitive and vulnerable in terms of stigmatization and self-stigmatization. It is known that such patients often experience difficulties in establishing close contacts with other people, finding employment, and adapting to a team. ${ }^{3}$

Activities aimed at restoring the social activity of patients can have a decisive impact on the maintenance of their rehabilitation potential, as well as a noticeable regression of the disease symptoms and faster recovery. ${ }^{4}$

The rehabilitation process for patients with a first psychotic episode is based on the principles of the biopsychosocial model of mental illness development, which also implies the implementation of psychosocial measures in addition to biological therapy. These arrangements should be aimed primarily at full or partial restoration of higher mental functions, socialization, and the patient's ability to form new capabilities, as well as the improvement of family relations, assistance in adapting to work, and educational activities. ${ }^{5}$

New areas of psychosocial rehabilitation have appeared in recent decades, significantly expanding the possibilities for providing care to patients with psychotic disorders, including avatar therapy, ${ }^{6}$ acceptance and commitment therapy, ${ }^{7}$ cognitive behavioural psychotherapy, ${ }^{8}$ metacognitive insight therapy, ${ }^{9}$ and neurocognitive training. ${ }^{10}$ All these methods have proven their efficiency and are included in the treatment guidelines for mental disorders in the health systems of many countries as the first choice for psychotherapeutic work with mental disorders. ${ }^{11,41}$

At present, cognitive behavioural therapy (CBT) has many different approaches within the method itself.
There are several areas of CBT, including dialectical behaviour therapy (DBT), ${ }^{12,13}$ mindfulness-based cognitive therapy (MBCT), ${ }^{14}$ and acceptance and commitment therapy (ACT). ${ }^{15}$ These approaches use mindfulness skills and based on the concept of contextual behavioural nature of the formation and maintenance of mental disorders. ${ }^{16}$

\section{BASIC PRINCIPLES AND CONCEPTS OF ACCEPTANCE AND COMMITMENT THERAPY}

Acceptance and commitment therapy (ACT) is a modern and relatively young psychological model and psychotherapeutic approach developed by Stephen Hayes, Kirk Strosahl, and Kelly Wilson. ${ }^{17}$ ACT is a form of behavioural therapy and a practical extension of functional contextualism philosophy, the theory of relational frames and development in applied behaviour analysis. ${ }^{18}$ ACT refers to the third wave of behavioural psychotherapy. Scientists worldwide have engaged in the study of ACT for various conditions in clinical practice are paying considerable attention to this area in the modern scientific community. ${ }^{19,20}$

Acceptance and commitment therapy is based on five key principles:

- acceptance

- cognitive defusion

- contact with the present moment

- self as context

- values and actions aimed at implementation of the values.

These principles and their interactions are often described by the term "hexaflex."21 The skills formed, in accordance with the described principles, can be united under the concept of "psychological flexibility."

There are several definitions of the concept of psychological flexibility in the literature. For example, 
Kashdan and Rottenberg define psychological flexibility as "a wide range of human abilities to recognize and adapt to various situational demands:

- to shift attention or change the behavioral scenario when required for social functioning and personal development;

- to be conscious, open to the inner experience and pursue personally meaningful goals and values through consistent behavior."22

Levin describes psychological flexibility as follows: "instead of direct attempts to change the frequency or intensity of unpleasant experiences (i.e. thoughts, feelings, sensations), the model of psychological flexibility is focused on changing of the people's reaction to the experience itself, breaking the connection between this experience and behavior, and reorienting the existing experience towards value-significant one." The main aim of this therapy is to teach the patient to live a rich and meaningful life, accepting the discomfort that inevitably accompanies it. The focus of therapy is always to improve productivity, despite the presence of any symptoms that might cause discomfort. ${ }^{23}$

Unlike other cognitive behavioral approaches, ACT does not aim to remove or reduce the intensity of symptoms. Symptom reduction is often achieved as an additional result rather than as the primary aim of treatment. The development of psychological flexibility, as the main objective of ACT, includes the acquisition of the following skills:

- recognition and adaptation to situational demands

- a shift of mind states or behavioural responses

- maintenance of the balance between relevant values

- the opportunity to be aware, open, and ready to act in accordance with one's own values.

Several comprehensive treatment guidelines have been developed since the late 1990s that describe how ACT can be used to treat a variety of mental disorders. ${ }^{24}$ Treatment with the use of these guidelines has been studied empirically and proven to be effective for a variety of clinical conditions:

- addictions

- depressive and anxiety disorders

- psychotic disorders

- chronic pain

- $\quad$ stress

- $\quad$ eating disorders. ${ }^{16}$

\section{ACT TECHNIQUES FOR TREATMENT} OF THE FIRST PSYCHOTIC EPISODE

Five main processes that are crucial to an individual changing are distinguished within ACT. ${ }^{25}$

\section{Acceptance}

The acceptance process describes the patient's willingness to allow the internal processes (feelings, emotions, thoughts) to be what they are, without any desire to change or influence them. For example, a patient with auditory hallucinations may begin to react to them (answer, obey the voice, try not to listen to the voice) in an attempt to regulate and control this unpleasant experience. The acceptance process is presented to patients as an alternative to attempts to control the positive symptoms and suggests going through unpleasant thoughts or emotions (listening to voices, observing anxious thoughts) without taking any action.

After termination of the acute psychotic state, patients may also face different painful experiences. Residual psychotic symptoms, post-psychotic depression, shame due to stigmatization, and somatic side effects of medication can all force the patient to use the experiential avoidance strategy (retire into oneself, break social ties, ignore symptoms of the disease, or, on the contrary, focus too much on them, use psychoactive substances, etc.), which only makes the discomfort worse.

The main purpose of the "acceptance" process is to change the patient's attitude towards a particular symptom, rather than an attempt to reduce the intensity of its manifestation. For this purpose to this end, the method of "creative hopelessness" is applied - a psychotherapeutic technique enabling the patient to give up their non-stop attempts to avoid unpleasant sensations and thoughts, and making it possible to withstand painful symptoms. ${ }^{26}$

\section{Cognitive defusion}

The term "cognitive fusion" refers to a person's tendency to merge with their thoughts in such a way that they take their content for truth or are immersed in them to such an extent that they are not capable of an alternative perception of the surrounding or inner realities. ${ }^{27}$

An example would be a person's inner voice telling them that they are crazy, dangerous, or uncontrollable. In this case, during the process of cognitive fusion, such a person will attach great importance to the content 
of these thoughts and arrange all reactions and behaviour based on them.

Cognitive defusion is a skill enabling a person to detach from the content of thoughts in order to be able to form a variety of mental reactions to what is happening.

There are two categories of cognitive defusion exercises. The first category is distancing and observation of the content of thoughts, enabling a person to avoid delving into the content of thoughts and instead record the circumstances of their appearance (under what circumstances they appear and how often). The second category is aimed at deliteralization of the language (departure from literality of the language) and enables destruction of the processes contributing to cognitive fusion, such as useless investigation of the reasons or meaningless and unnecessary self-assessment. ${ }^{28}$

\section{Contact with the present moment}

The ability to be "here and now" is a skill that enables the individual to focus attention purposefully on internal and external events at the present moment, without commentary on or evaluation of what is happening. Due to this skill, conditions for contact with thoughts, feelings, and sensations are created, and the reaction to their content is attenuated. ${ }^{29}$

There are special exercises for training the skill of contact with the present moment. A patient is asked to select an object of attention, and make an effort to hold attention on that object for a short period of time. For example, a patient is asked to notice 10-15 objects in the room in order to focus on external sourses of information. In order to concentrate on internal processes, a patient is asked to feel five smells and listen to five sounds. ${ }^{21}$

\section{Self as context}

Behavioural responses often result from the selfconcept; a person identifies themselves with the role that they are in. For example, a person with a mental illness might say "I'm crazy." This statement means that this person fully identifies themselves with the experience of living with the disease and does not remember any good or significant moments in their life when they were not ill.

The aim of acceptance and commitment therapy is to form an observing part of the personality that perceives the inner and outer world separately from one's thoughts, feelings, memories, physical sensations, and roles of a person. Observing attitude exercises enables the individual to create the experience of safe contact with uncomfortable and unwanted inner feelings. ${ }^{30}$

\section{Values and actions aimed at implementation of values}

The term "values" means the selected areas of activities defined by a person as significant and important to them. ${ }^{30}$ Values determine what a person wants to be, and what kind of life they want to live.

Within the framework of the ACT model, contact with values is one of the most important aspects of psychological flexibility. ${ }^{27}$ Patients experiencing a first psychotic episode are going through a painful experience, and can lose their connection with values and waste their resources on coping with these painful feelings. Finally, a patient may believe that their value-oriented behaviour is possible only upon improvement of their condition, which is often impossible due to mental illness implying a certain level of discomfort. ${ }^{31}$

Acceptance and commitment therapy teaches patients to restore their contact with values and to arrange their behavioral in accordance with them, despite the presence of any discomfort.

ACT uses the entire range of behavioural possibilities in working with value-oriented actions:

- planning

- $\quad$ keeping a diary of productive actions

- functional analysis of possible failures

- motivational interventions. ${ }^{32}$

Thus, the six processes listed above are the key components for the development of psychological flexibility in a person suffering from any mental illness.

Researchers suggest that psychological inflexibility is one of the factors reducing the routine functioning ability of people with mental disorders. ${ }^{33}$ Studies show that psychological inflexibility is a contributing factor to distress and may be associated with the poor functioning of people with psychotic experiences. ${ }^{27}$ ACT considers the problem of distress associated with psychotic experiences as a consequence of psychological inflexibility, when a person goes through a life situation in a limited manner due to continuous and excessive avoidance, too literal an interpretation of their own experience, a failure to understand where to move in life, and/or when the person has surrendered and experiences difficulties in taking any actions with a long- 
term perspective. The content of experiences (in the case of hallucinations) or painful inferences (delusions) makes it necessary to avoid or control them, thus increasing the effect of the symptom itself.

In the treatment of psychotic disorders, ACT helps to develop an acceptance technique that patients can apply upon the occurrence of any psychotic experiences, and assists in the development of a specific style of attitude towards uncontrollable events. ACT encourages a person to switch from the repression and control strategy towards the achievement of contact with their feelings and experiences. As far as coping with psychotic symptoms is concerned, ACT encourages a patient to direct their behaviour to their own chosen values instead of merging with painful experiences, even if painful feelings remain.

Thus, the purpose of the application of ACT is not to confront painful thoughts or sensations, but rather to teach the skills of acceptance, keeping in touch with the present moment, and understanding unwanted symptoms and manifestations as a part of life and not the reason to pause all life in order to fight them. ${ }^{34}$

\section{ACT EFFICIENCY EVIDENCE}

The effect of ACT on patient readmission was investigated during an early study. ${ }^{35}$ The application of ACT resulted in a $50 \%$ increase in the intervals between hospitalizations (22 days longer) in comparison with the treatment as usual group (drug therapy and psychoeducation). A later study performed by Gaudiano and Herbert in 2006 showed an improvement of only $38 \% .^{8}$ In order to eliminate bias, the researchers additionally tested the participants involved in the study, which showed that the group of patients receiving ACT included patients with both high and low rehospitalization rates. ${ }^{36}$

In addition, 50\% of the patients receiving ACT significantly improved their Brief Psychiatric Rating Scale (BPRS) scores, compared to $7 \%$ in the control group. ${ }^{35}$ Similar results were obtained in remove the course of another study conducted in 2013. ${ }^{37}$

Recent retrospective studies have added supplementary data to these results. Tyrberg et al. used the rehospitalization rates within four months of discharge as the main criterion for their efficiency assessment. They also found that patients receiving ACT in addition to the basic treatment demonstrated a reduction in rehospitalization rates. Drug therapy persistence and the influence of this factor on treatment outcomes were also investigated. There were no significant differences between the groups, indicating that a higher persistence level did not explain the reduction in the readmission rates. ${ }^{38}$

Two studies were devoted to a review of patients' selfreports on the degree of belief in the content of positive symptoms. ${ }^{35,36}$ Only one of them confirmed a significant decrease in confidence with regard to the veracity of the content of these symptoms after treatment. ${ }^{36}$ In addition, according to the study by Gaudiano and Herbert, ${ }^{35}$ distress was also considerably reduced after ACT, but this change was not significant according to the study by Bach and Hayes. ${ }^{36}$ The frequency of symptom reporting was measured and was considerably higher in the group of patients receiving ACT. ${ }^{36}$ The authors note that this is expected within the framework of the ACT model, since this approach normalizes the psychotic experience while the traditional view towards the treatment of schizophrenia spectrum disorders interprets such phenomena as a sign of deterioration or even disease recurrence. The researchers point out the fact that the number of symptoms most likely remains the same, but due to the normalization of the psychotic experience and the activities to reduce its avoidance, it becomes easier for patients to track the symptoms without fear of reporting them, thus helping to increase treatment persistence and to prevent recurrence. More recent studies using data consolidated from the previous ones have shown that the degree of belief in the content of hallucinations and delusions directly affects both the severity of the distress associated with a psychotic experience, and the duration of remission and a reduction in the number of hospital readmissions. ${ }^{39}$

These results are complemented by Gaudiano et al., who found that despite the permanent frequency of reports on hallucinations, 55\% of patients receiving ACT no longer met the criteria for post-psychotic depression; this also significantly affects the reduction of distress arising from the presence of psychotic symptoms. ${ }^{37}$ The study by White showed that the condition of patients from the comparison group not receiving ACT was still meeting the criteria for post-psychotic depressive disorder during the three-month follow-up period, while in the group of patients receiving ACT this figure was only $20 \% .40$

The effect of ACT on psychosocial functioning and mood swings has also been examined. The results 
of the study by Johns et al. showed improvements in both parameters. ${ }^{41} \mathrm{~A}$ significantly lower percentage of patients in the ACT group met the criteria for postpsychotic depressive disorder as compared to the control group at all stages of follow-up (during and after treatment). ${ }^{36,42}$ White et al. found that there were also considerably fewer complaints among the patients receiving ACT. Subsequent to the results of observation within three to nine months after treatment, all studies confirm sustainable improvement in functioning and emotional status; these parameters were much better than in the associated control groups. ${ }^{40}$

\section{LIMITATIONS OF AVAILABLE RESEARCH AND PROSPECTS FOR FURTHER RESEARCH}

Five of the 13 studies included in the most relevant systematic review to date contain a reanalysis of the existing data as well as overlapping data, i.e., no new material has been collected in these studies, meaning that they are based either on the data from the follow-up period, or the existing material analysed via alternative statistical methods. It is important to note that the data from more recent studies have confirmed the results of the previous ones. The follow-up period after treatment ranged from three months to one year. ${ }^{43}$ Thus, there is a lack of new data meeting the most stringent criteria for research, which undoubtedly justifies the need for further and longer observations to assess the effectiveness of ACT in the longer term.

Criticism of the available studies mainly focuses on the small sample sizes and significant differences in the number of subjects from study to study, ranging from 120 to $14 .{ }^{37,44}$ In addition, a certain number of participants dropped out of certain studies, subsequently having a significant impact on sample sizes that were already small. ${ }^{45}$ The heterogeneity of the scales used by the researchers is also noted. In the various studies by Gaudiano et al., the parameters used for assessment of the treatment outcomes differ, $35-37,41$ making it difficult to cross-check the available data for their assessment and analysis in metaanalytical reviews. ${ }^{43}$

In the studies reviewed, ACT has been used in various forms, for both a short term of two to four sessions, 31,32,41 and for a longer term of 10-24 sessions. 21,35,36,42

Due to these objective limitations, the aim of future research should be the expansion of the sampled population under study and the establishment of unified methodological instruments in both the assessment of the state and the applied statistical methods.

\section{PRACTICAL EXPERIENCE OF USING ACT FOR PATIENTS EXPERIENCING A FIRST PSYCHOTIC EPISODE IN RUSSIA}

Since 2017, ACT protocols were adapted and used in the First Psychotic Episode Clinic at Mental Health Clinic No.1, named after N.A. Alexeev, as a part of treatment protocol for patients experiencing their first psychotic episode. ${ }^{46}$

The ACT programme is used in an inpatient department in the format of individual consultations, in the day hospital and outpatient departments of the Clinic, and is in the form of a group therapy format (the name of the programme "Training on the development of emotional self-regulation skills").

Further, we describe the format and content of the "Training for the development of emotional self-regulation skills" in the day hospital. This programme was formed on the basis of existing programmes developed in foreign clinics for treatment of patients experiencing their first psychotic episode. ${ }^{34,46}$

The training consists of four sessions, with an additional session to include new participants. The group is semiopen and includes up to 12 people (an even number of participants is important, since many exercises are paired). Each session lasts one hour, including a "warmup" at the beginning and discussion of homework at the end of the session; sessions are held twice a week.

The training uses the methods of group discussion, role play, as well as the presentation of theoretical material in the form of interactive lectures. Theoretical interactive mini-lectures are alternated with practical training of the necessary skills, namely to stay in the present moment, to notice the events of one's inner life, separation, mindfulness, neutral self-observation, and implementation of value-oriented actions.

\section{Session 1. Skills of being in the observer position} During this training the theoretical foundations of the concept of "psychological flexibility" are studied. It is understood as "a wide range of human capabilities to recognize and adjust to the requirements of the situation; switch attention or change the scenario of behavior when it is required for social functioning and personal development; be conscious, open to inner 
experience and realize personally meaningful goals and values through consistent behavior."

Non-constructive ways of interacting with negative thoughts and feelings are studied; for instance, fusion and avoiding fighting. The patients also train the experience of interacting with the new position of an observer. Having taken the position of an observer, the patient can distance themselves from negative thoughts and feelings and then begin to work with them.

\section{Session 2. Learning to untangle from negative thoughts and their content}

This training discusses the effect of negative thoughts and feelings on an individual. Exercises are conducted with patients to separate problems that can be influenced (wash dishes, clean the apartment) and which cannot be influenced (crisis, migration, war). If external circumstances are beyond the patient's control and it is impossible to solve the problem constructively, then the patient should focus on internal work. The patient is offered the following algorithm of actions: notice a negative thought or emotion; remind yourself that this is just a thought, not a reality; to separate oneself from an unpleasant thought with the help of the proposed techniques, reducing its significance, perceiving it in a different way (for example, as a sound). The patient is invited to try to control thoughts and feelings in order to understand that it is impossible. A facilitator leads the patient to the conclusion that it is only possible to control reactions to thoughts and feelings and behavior, but not thoughts and feelings themselves. The observer position skill allows the creation of distance from, and the reduction of the negative pressure on the psyche, which in turn allows the problem to be solved.

\section{Session 3. Working with self-criticism and self-support}

The purpose of this training is to educate patients about the origin and function of complex experiences such as shame and self-criticism, how these experiences affect the emergence of anxious and depressive thoughts in the individual, and provoke self-stigmatization in relation to mental illness. With the help of group exercises, internal ideas are formed that an individual's negative selfperceptions entail consequences such as unwillingness to comply with drug therapy and more frequent hospitalizations. Then, together with the patients, the image of the criticizing inner voice is examined, and then transformed to an assistant in solving difficult problems and problems associated with the disease. Thus, a new image of the internal assistant is created, and algorithms for interaction with its supporting role are developed.

\section{Session 4. Working with values}

The group examines the concept of values, how they are formed, and where they come from. Further, a classification of values is created and those that can be implemented at this stage of the treatment (hospital, day hospital, outpatient clinic) are identified. It is important to focus patients' attention on the fact that while on treatment, they support good health, which is one of their main values. Then, a set of actions is created to realize the selected value in the "here and now" mode. Also, possible obstacles are determined, negative thoughts and emotions that can interfere with the implementation of what the patient has planned are identified. As a homework assignment, patients are asked to take actions every day to realize one of their chosen values. If negative thoughts and emotions get in the way, patients are encouraged to work with them using the exercises they learned during the training sessions.

At the outpatient treatment, the patient continues to attend the "Training for the development of emotional self-regulation skills" program. However, the format of this group is one of supportive follow-up. The group becomes open and patients can visit for an unlimited time.

Thus, at all stages of treatment at the First Psychotic Episode Clinic, patients learn to form and develop selfobservation skills; develop skills of flexible response to emerging undesirable, unpleasant events of inner life (negative emotions, thoughts, beliefs, voices and hallucinations, physical sensations); expand their behavioral repertoire; form the motivation to study and follow those areas of life that are consistent with the patient's personal values; and improve their quality of life by focusing attention on positive, useful and meaningful experiences.

\section{CONCLUSION}

An analysis of the research devoted to the problem of the first psychotic episode and the state of psychiatric care for patients experiencing their first psychotic episode shows that this subject area is an important field of research in psychiatry and psychotherapy. The initial period of the 
disease forms and predetermines its long-term prognosis and therefore in many countries this category of patients forms a separate group for which special therapeutic approaches have been developed. In Russia, the First Psychotic Episode Programme, based on the principle of step-by-step polyprofessional psychiatric care with an emphasis on outpatient care, early involvement of psychosocial therapy, and the use of new generation antipsychotics for the relief of psychotic symptoms and subsequent supportive therapy, has also been developed and tested.

Meta-analysis of the data has shown that psychological inflexibility is a contributing factor to level of distress and may be associated with the poor functioning of people with psychotic experiences. ACT considers the problem of distress associated with the psychotic experience as a lack of psychological flexibility when a person goes through any life situation using a limited repertoire of reactions. The results of randomized controlled studies show that ACT is effective at reducing the distress related to both productive symptoms and associated behavior. Moreover, the efficiency of ACT is sustainable both for the individual and the group therapy formats, in the brief therapy format, ranging from four to 24 meetings, and in inpatient and outpatient treatment. The results also indicate a decrease in the readmission rates and the improvement of patients' psychosocial functioning.

Thus, the application of acceptance and commitment therapy is justified for use within the framework of psychosocial rehabilitation for patients suffering from chronic mental disorders and patients experiencing their first psychotic episode.

\section{Article history:}

Submitted: 21.07.2021

Accepted: 08.09.2021

Published: 16.12 .2021

Funding: The study was performed without external funding.

Conflict of interests: The authors report no conflicts of interest.

Authors' contributions: N.V. Chernov - conception of the paper; T.V. Moiseeva - editing the manuscript; M.D. Polyakova, M.V. Sozinova - obtaining data and writing the manuscript; M.A. Belyakova - obtaining data from international sources and analyzing the results of the research.

\section{For citation:}

Chernov NV, Moiseeva TV, Belyakova MA, Polyakova MD, Sozinova MV. Acceptance and Commitment Therapy for Patients with a First Psychotic Episode. Consortium Psychiatricum. 2021;2(4):30-39. doi: 10.17816/CP97

\section{Information about authors}

M.V. Sozinova, Department of psychotherapy and social rehabilitation, Mental Health Clinic No.1 named after N.A. Alexeev, Moscow, Russia, ORCID: https://orcid.org/0000-0003-4990-8725

T.V. Moiseeva, PhD in psychology, psychologist, department of psychotherapy and social rehabilitation, Mental Health Clinic No.1 named after N.A. Alexeev, Moscow, Russia, ORCID: https://orcid.org/0000-0001-7577-0884, Scopus Author ID: 57211412298

M.A. Belyakova, psychologist, department of psychotherapy and social rehabilitation, Mental Health Clinic No.1 named after N.A. Alexeev, Moscow, Russia, ORCID: https://orcid.org/0000-0001-5687-9139

M.D. Polyakova, psychologist, department of psychotherapy and social rehabilitation, Mental Health Clinic No.1 named after N.A. Alexeev, Moscow, Russia, ORCID: https://orcid.org/0000-0002-7520-0168

\section{Correspondence to:}

N.V. Chernov, Head of the Department of Psychotherapy and Social Rehabilitation, Mental Health Clinic No.1 named after N.A. Alexeev, Moscow, Russia, ORCID: https://orcid.org/0000-0001-5347-0231, Scopus Author ID: 83220238152

E-mail: n.chernov.psy@bk.ru

\section{References}

1. World Health Organization. International classification of diseases for mortality and morbidity statistics (11th Revision). Accessed September 7, 2021. https://icd.who.int/browse11//-m/en

2. Vujnovic M, Manukhina O, Reed GM, Theodorakis PN, Fountoulakis KN. ICD-11 Revision of Mental Disorders: the Global Standard for Health Data, Clinical Documentation, and Statistical Aggregation. Consortium Psychiatricum. 2021;2(2):3-6. doi: 10.17816/cp74

3. Neznanov NG, Shmukler AB, Kostyuk GP, Sofronov AG. Pervyi psikhoticheskii epizod: epidemiologicheskie aspekty organizatsii pomoshchi. Social and clinical psychiatry. 2018;28(3):5-11.

4. Gaudiano BA, Miller IW, Herbert JD. The treatment of psychotic major depression: is there a role for adjunctive psychotherapy? Psychother Psychosom. 2007;76(5):271-277. doi: 10.1159/000104703

5. Shashkova NG, Gazha AK. Pervyi psikhoticheskii epizod: osobennosti okazaniya psikhiatricheskoi pomoshchi bol'nym v sovremennykh usloviyakh. Social and clinical psychiatry. 2020;30(2):80-90.

6. Craig TK, Rus-Calafell M, Ward T, et al. AVATAR therapy for auditory verbal hallucinations in people with psychosis: a single-blind, randomised controlled trial. Lancet Psychiatry. 2018;5(1):31-40. doi: 10.1016/S2215-0366(17)30427-3 
7. Bach P, Gaudiano BA, Hayes SC, Herbert JD. Acceptance and commitment therapy for psychosis: intent to treat, hospitalization outcome and mediation by believability. Psychosis 2013;5(2):166-174. doi: 10.1080/17522439.2012.671349

8. Gaudiano BA, Herbert JD. Believability of Hallucinations as a Potential Mediator of Their Frequency and Associated Distress in Psychotic Inpatients. Behavioural and Cognitive Psychotherapy. 2006;34(04):497. doi: 10.1017/s1352465806003080

9. Moritz S, Klein JP, Lysaker PH, Mehl S. Metacognitive and cognitive-behavioral interventions for psychosis: new developments. Dialogues Clin Neurosci. 2019;21(3):309-317. doi: 10.31887/DCNS.2019.21.3/smoritz

10. Zaitseva YuS, Korsakova NK, Gurovich IYa. Neirokognitivnoe funktsionirovanie na nachal'nykh etapakh shizofrenii i kognitivnaya remediatsiya. Social and clinical psychiatry. 2013;23(4):76-87.

11. Maggie M. The Dialectical Behavior Therapy Skills Workbook for Psychosis: Manage Your Emotions, Reduce Symptoms, and Get Back to Your Life. New Harbinger Publications; 2021.

12. Kuckertz JM, Silverman AL, Bullis JR, Bjorgvinsson T, Beard C. Awareness of and attitudes toward CBT, DBT, and ACT in an acute psychiatric sample. J Clin Psychol. 2020;76(4):749-768. doi: $10.1002 / j c l p .22908$

13. Holbrook AM, Hunt SR, See MR. Implementation of Dialectical Behavior Therapy in Residential Treatment Programs: A Process Evaluation Model for a Community-Based Agency. Community Ment Health J. 2018;54(7):921-929. doi: 10.1007/s10597-017-0224-6

14. Goldberg SB, Tucker RP, Greene PA, et al. Mindfulness-based interventions for psychiatric disorders: A systematic review and meta-analysis. Clin Psychol Rev. 2018;59:52-60. doi: 10.1016/j.cpr.2017.10.011

15. Villatte JL, Vilardaga R, Villatte $M$, et al. Acceptance and Commitment Therapy modules: Differential impact on treatment processes and outcomes. Behav Res Ther. 2016;77:52-61. doi: 10.1016/j.brat.2015.12.001

16. Ducasse D, Fond G. Acceptance and commitment therapy. Article in French. Encephale. 2015;41(1):1-9. doi: 10.1016/j.encep.2013.04.017

17. Hayes SC, Strosahl K, Wilson KG. Acceptance and Commitment Therapy: An experiential approach to behavior change. Guilford Press; 1999.

18. Feliu-Soler A, Montesinos F, Gutierrez-Martinez O, et al. Current status of acceptance and commitment therapy for chronic pain: a narrative review. J Pain Res. 2018;11:2145-2159. doi: 10.2147/JPR.S144631

19. Shawyer F, Farhall J, Mackinnon A, et al. A randomised controlled trial of acceptance-based cognitive behavioural therapy for command hallucinations in psychotic disorders. Behav Res Ther. 2012;50(2):110-121. doi: 10.1016/j.brat.2011.11.007

20. Fung K. Acceptance and Commitment Therapy: Western adoption of Buddhist tenets? Transcult Psychiatry. 2015;52(4):561-576. doi: 10.1177/1363461514537544

21. Hayes SC, Luoma JB, Bond FW, Masuda A, Lillis J. Acceptance and commitment therapy: model, processes and outcomes. Behav Res Ther. 2006;44(1):1-25. doi: 10.1016/j.brat.2005.06.006

22. Kashdan TB, Rottenberg J. Psychological flexibility as a fundamental aspect of health. Clin Psychol Rev. 2010;30(7): 865-878. doi: 10.1016/j.cpr.2010.03.001

23. Levin ME, Hildebrandt MJ, Lillis J, Hayes SC. The impact of treatment components suggested by the psychological flexibility model: a meta-analysis of laboratory-based component studies. Behav Ther. 2012;43(4):741-756 doi: 10.1016/j.beth.2012.05.003

24. McKay M, Greenberg MJ, Fanning P. The ACT Workbook for Depression and Shame: Overcome Thoughts of Defectiveness and Increase Well-Being Using Acceptance and Commitment Therapy. New Harbinger Publications; 2020.

25. Hayes SC, Strosahl K, Wilson KG. Acceptance and Commitment Therapy: An experiential approach to behavior change. Guilford Press; 1999.

26. Lillis J, Hayes SC. Applying acceptance, mindfulness, and values to the reduction of prejudice: a pilot study. Behav Modif. 2007;31(4):389-411. doi: 10.1177/0145445506298413

27. Dindo L, Van Liew JR, Arch JJ. Acceptance and Commitment Therapy: A Transdiagnostic Behavioral Intervention for Mental Health and Medical Conditions. Neurotherapeutics. 2017;14(3):546-553. doi: 10.1007/s13311-017-0521-3

28. Luoma JB, Hayes SC. Cognitive defusion. In: O' Donohue W, Fisher J, Hayes SC, eds. Cognitive behavior therapy: Applying empirically supported techniques in your practice. John Wiley \& Sons; 2003:37-73.

29. Wielgosz J, Goldberg SB, Kral TRA, Dunne JD, Davidson RJ. Mindfulness Meditation and Psychopathology.

Annu Rev Clin Psychol. 2019;15:285-316. doi: 10.1146/annurev-clinpsy-021815-093423

30. Hayes S, Strosahl K, Wilson K. Acceptance and commitment therapy: the process and practice of mindful change. Guilford Press; 2011.

31. Bora E, Yalincetin B, Akdede BB, Alptekin K. Duration of untreated psychosis and neurocognition in first-episode psychosis:

A meta-analysis. Schizophr Res. 2018;193:3-10. doi: 10.1016/j.schres.2017.06.021

32. Luoma JB, Hayes SC, Walser RD. Learning ACT: An Acceptance and Commitment Therapy skills-training manual for therapists. Harbinger Publications; 2007.

33. JG AT, Davis ML, Morina N, et al. A meta-analysis of the efficacy of acceptance and commitment therapy for clinically relevant mental and physical health problems. Psychother Psychosom. 2015;84(1):30-36. doi: 10.1159/000365764

34. O'Donoghue EK, Morris EMJ, Oliver JE, Johns LC. ACT for psychosis recovery: A practical manual for group-based interventions using acceptance and commitment therapy. Context Press/New Harbinger Publications; 2018.

35. Gaudiano BA, Herbert JD. Acute treatment of inpatients with psychotic symptoms using Acceptance and Commitment Therapy: pilot results. Behav Res Ther. 2006;44(3):415-437. doi: 10.1016/j.brat.2005.02.007

36. Bach P, Hayes SC. The use of acceptance and commitment therapy to prevent the rehospitalization of psychotic patients: a randomized controlled trial. J Consult Clin Psychol. 2002;70(5):1129-1139. doi: 10.1037//0022-006x.70.5.1129

37. Gaudiano BA, Nowlan K, Brown LA, Epstein-Lubow G, Miller IW. An open trial of a new acceptance-based behavioral treatment for major depression with psychotic features. Behav Modif. 2013;37(3):324-355. doi: 10.1177/0145445512465173

38. Tyrberg MJ, Carlbring P, Lundgren T. Brief acceptance and commitment therapy for psychotic inpatients: A randomized controlled feasibility trial in Sweden. Nordic Psychology. 2016;69(2):110-125. doi: 10.1080/19012276.2016.1198271

39. Gaudiano BA, Herbert JD, Hayes SC. Is it the symptom or the relation to it? Investigating potential mediators of change in acceptance and commitment therapy for psychosis. Behav Ther 2010;41(4):543-554. doi: 10.1016/j.beth.2010.03.001 
40. White R, Gumley A, McTaggart J, et al. A feasibility study of Acceptance and Commitment Therapy for emotional dysfunction following psychosis. Behav Res Ther. 2011;49(12):901-907. doi: 10.1016/j.brat.2011.09.003

41. Johns LC, Oliver JE, Khondoker M, et al. The feasibility and acceptability of a brief Acceptance and Commitment Therapy (ACT) group intervention for people with psychosis: The 'ACT for life' study. J Behav Ther Exp Psychiatry. 2016;50:257-263. doi: 10.1016/j.jbtep.2015.10.001

42. Gaudiano BA, Busch AM, Wenze SJ, et al. Acceptance-based Behavior Therapy for Depression With Psychosis: Results From a Pilot Feasibility Randomized Controlled Trial. J Psychiatr Pract. 2015;21(5):320-333. doi: 10.1097/PRA.0000000000000092

43. Wakefield S, Roebuck S, Boyden P. The evidence base of Acceptance and Commitment Therapy (ACT) in psychosis:
A systematic review. Journal of Contextual Behavioral Science. 2018;10:1-13. doi: 10.1016/j.jcbs.2018.07.001

44. Bach P, Gaudiano BA, Hayes SC, Herbert JD. Acceptance and commitment therapy for psychosis: intent to treat, hospitalization outcome and mediation by believability. Psychosis. 2013;5(2):166-174. doi: 10.1080/17522439.2012.671349

45. Gray R, Shrestha M, Brown E. Acceptance- and mindfulness-based interventions for persons with psychosis: Potential errors in reported meta-analyses. Schizophr Res. 2020 Aug;222:522. doi: 10.1016/j.schres.2020.05.021. PMID: 32444203.

46. Oliver J, Morris E, Johns L, Byrne M. ACT For Life Group Intervention for Psychosis Manual (2011). Accesed September 7, 2021. https://contextualscience.org/quotact_for_lifequot_group_ intervention_for_psycho 